\title{
1 Supramolecular Complexation of Carbon Nanostructures by Crown 2 Ethers
}

\author{
${ }_{3}$ Luis Moreira, $^{\dagger}$ Beatriz M. Illescas, $^{\dagger}$ and Nazario Martín ${ }^{*},,+(0)$ \\ $4{ }^{\dagger}$ Departamento de Química Orgánica, Facultad de Química, Universidad Complutense de Madrid, E-28040 Madrid, Spain \\ 5 IIMDEA-Nanoscience, C/Faraday, 9, Campus de Cantoblanco, E-28049 Madrid, Spain
}

6 ABSTRACT: Since their discovery, crown ethers as well as the most recent carbon nanostructures, namely fullerenes, carbon nanotubes, and graphene, have received a lot of attention from the chemical community. Merging these singular chemical structures by noncovalent forces has provided a large number of unprecedented supramolecular assemblies with new geometric and electronic properties whose more representative examples are presented in this Synopsis organized according to the different nature of the carbon nanostructures.

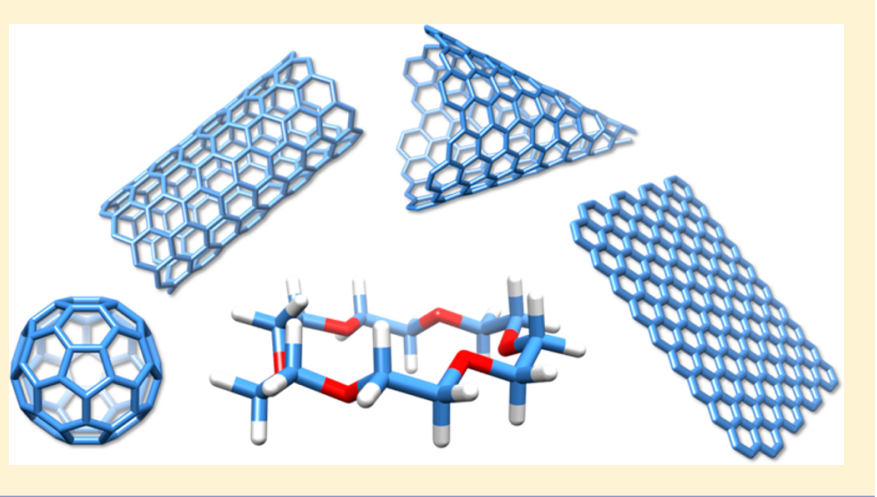

Bethune in $1993^{7,8}$ became important milestones. More 38 recently, the aforementioned findings have been complemented 39 with the discovery of graphene by Geim and Novoselov in 40 $2004,{ }^{9}$ which was awarded with the Nobel Prize in Physics in 41 2010.

Although many different forms of carbon are known, ${ }^{10}$ we 43 will mainly focus our attention on fullerene and its endohedral 44 derivatives, carbon nanotubes, carbon nanohorns, and graphene 45 (Figure 1).

Given the extraordinary properties of the aforementioned 47 nanostructures, it is not surprising that chemists have combined 48 them together in the search for unprecedented systems. In this 49 Synopsis, we will pinpoint the most relevant examples of their 50 supramolecular complexation by crown ethers.

\section{FULLERENES}

52

Fullerenes are one of the most widely used electron-acceptor 53 molecules given their outstanding electronic properties, namely 54 small reorganization energy, ${ }^{11}$ low reduction potential, ${ }^{12} 55$

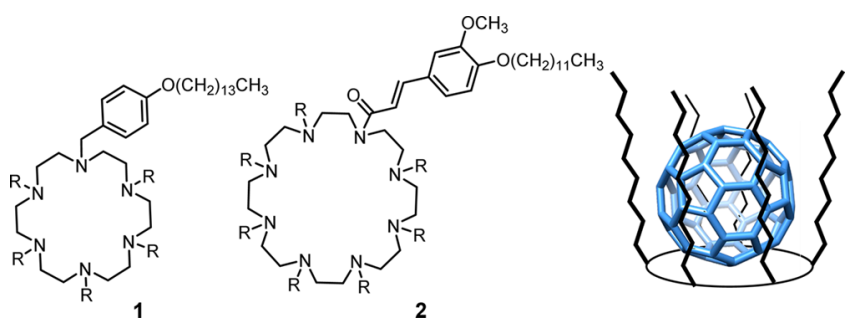

Figure 2. Azacrown ethers used to bind fullerenes and scheme of the supramolecular "basket" envisioned for the 1:1 complex.

Received: December 20, 2016

Published: February 16, 2017 
Table 1. Stability Constants for a Series of 1:1 [60]Fullerene ${ }^{C}$ Crown Ether Complexes ${ }^{a}$

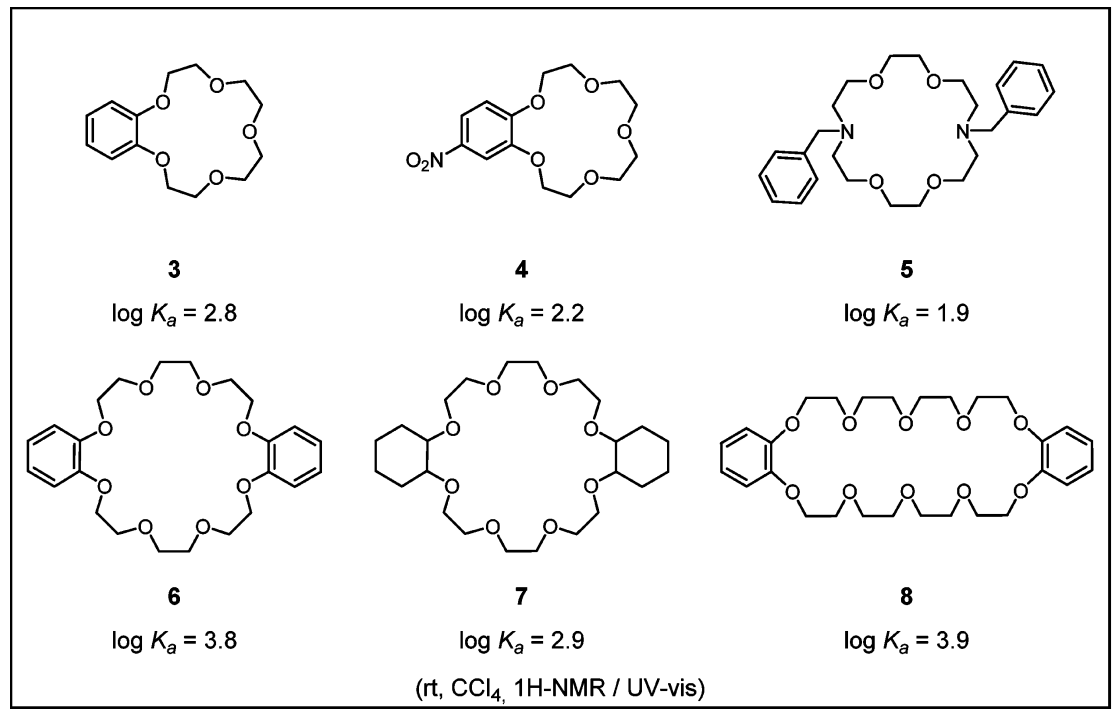

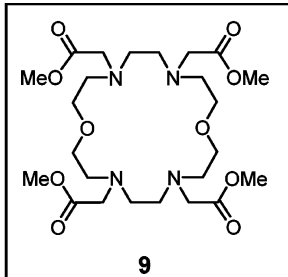

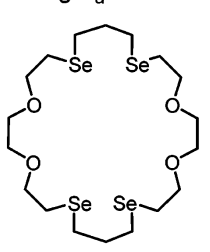

11

$\log K_{a}=3.2$

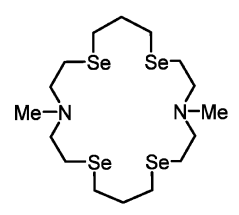

10

$\log K_{a}=3.3$

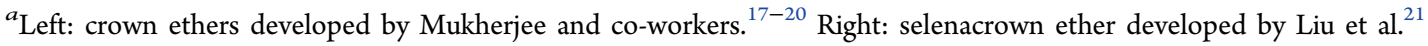

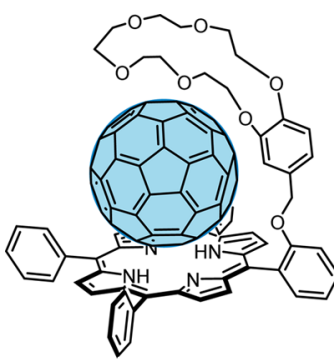

$\left[13 \cdot \mathrm{C}_{60}\right]$ $\log K_{a}=3.9$

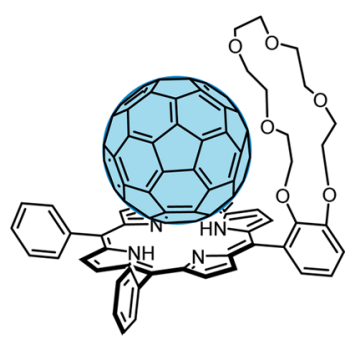

[14. $\left.\mathbf{C}_{60}\right]$

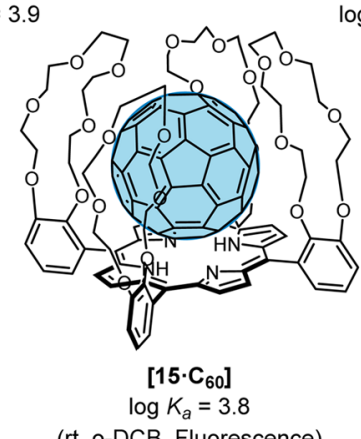

(rt, o-DCB, Fluorescence)

Figure 3. Crown ether appended free-base porphyrin-fullerene donor-acceptor complexes.

Scheme 1. $\mathrm{K}^{+}$-Induced Switching of Intra- to Intermolecular Association (Forward Reaction) and [18] Crown-6-Induced Reversible Switching (Backward Reaction)

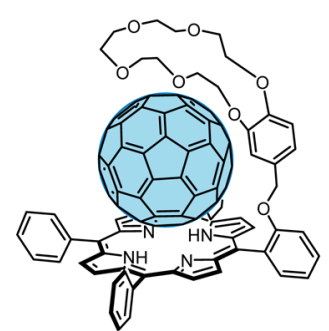

Moderate intramolecular interactions
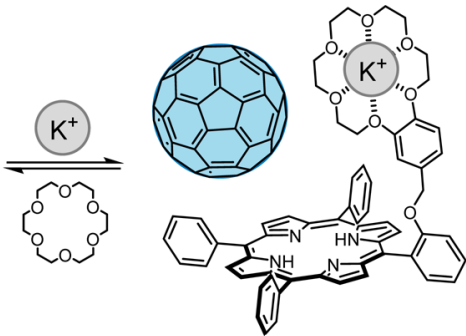

Weak intramolecular interactions

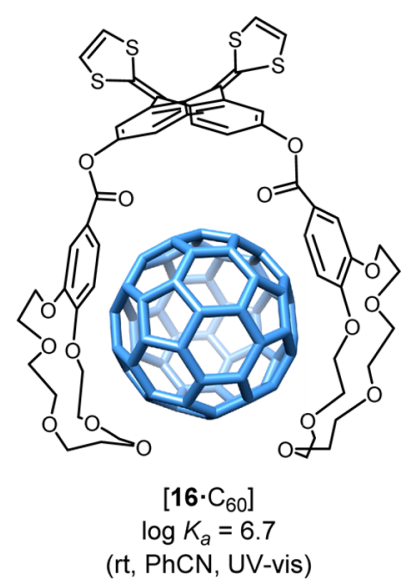

Figure 4. Combination of crown ethers and exTTF as recognition motifs led to robust complexation of $\mathrm{C}_{60}$.

appreciable absorption cross section throughout the solar 56 spectrum, ${ }^{13}$ and efficient generation of long-lived charge- 57 separated states. ${ }^{14,15}$ Furthermore, their spherical geometry 58 and remarkable hydrophobicity make them appealing systems 59 for 3D supramolecular interactions.

Pristine fullerenes were complexed for the first time with 61 azacrown ethers 1 and 2 bearing long lipophilic chains on the 62 nitrogens (Figure 2). The ability of these systems to act as $63 \mathrm{f} 2$ supramolecular "baskets" was suggested by Effing et al. in view 64 of the additional stability of the crown ether's Langmuir- 65 Blodgett films upon addition of fullerenes. ${ }^{16}$

Following this pioneering work, Mukherjee and co-workers 67 synthesized a series of crown ethers 3-8 to evaluate their 68 affinity toward fullerenes, finding that larger cavities and 69 preorganized systems led to larger binding constants $\left(K_{\mathrm{a}}\right)$ and 70 that complexation occurred with the involvement of an 71 electron-transfer process (Table 1, left). ${ }^{17-20} \mathrm{Liu}$ et al. also $72 \mathrm{t} 1$ observed this size-dependence relationship in a series of 73 selenacrown ethers 9-12 and a better stabilization upon 74 introduction of the heteroatoms (Table 1, right). ${ }^{21} 75$

D'Souza et al. further exploited this affinity with molecular 76 receptors 13-15 (Figure 3). Addition of porphyrins as a $77 \mathrm{f3}$ 
Scheme 2. Series of exTTF-(crown ether) ${ }_{2}$ Molecular Tweezers Designed To Host $\mathrm{C}_{60}$<smiles>CC(C)(C)C</smiles>

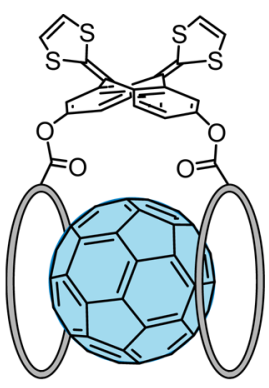<smiles>[I-]c1ccccc1</smiles><smiles>Ic1ccc2c(c1)OCCOCCOCCOCCO2</smiles>

17 $\log K_{a}=4.8$<smiles>CCOCCOCCOCCOCCOCNc1ccc(C)cc1</smiles>

20 $\log K_{a}=5.1$<smiles>CC1C=CC(N2CCOCCOCCOCCOCC2)CC1</smiles>

18

$\log K_{a}=3.8$<smiles>CCCOCCOc1ccc(I)cc1OCCOCCOCCOc1ccccc1O</smiles>

$\log K_{a}=6.9$

(rt, CIPh, UV-vis)<smiles>Cc1ccc2c(c1)OCCOCCOCCOCCOCCO2</smiles>

19

$\log K_{a}=6.7$

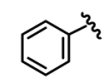

22

$\log K_{a}=3.3$ a)

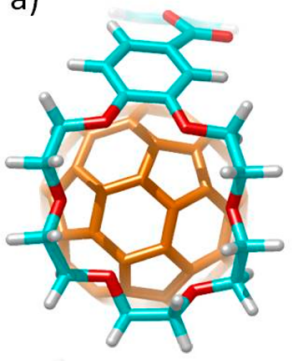

b)

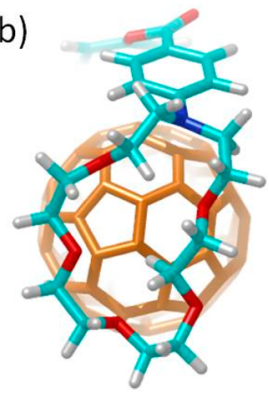

c)

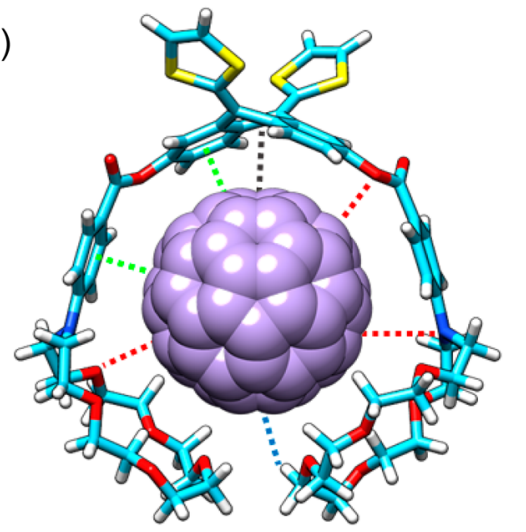

Figure 5. Side view of the optimized geometries calculated for complexes $\left[19 \cdot C_{60}\right](a)$ and $\left[20^{\circ} C_{60}\right](b)$. The affinity of our receptors arises as an interplay of donor-acceptor (black), $\pi-\pi$ (green), n- $\pi$ (red), and $\mathrm{CH} \cdots \pi$ (blue) interactions (c).
Scheme 3. pH-Dependent Reversible Threading of the First Supramolecular Fullerene Dyad
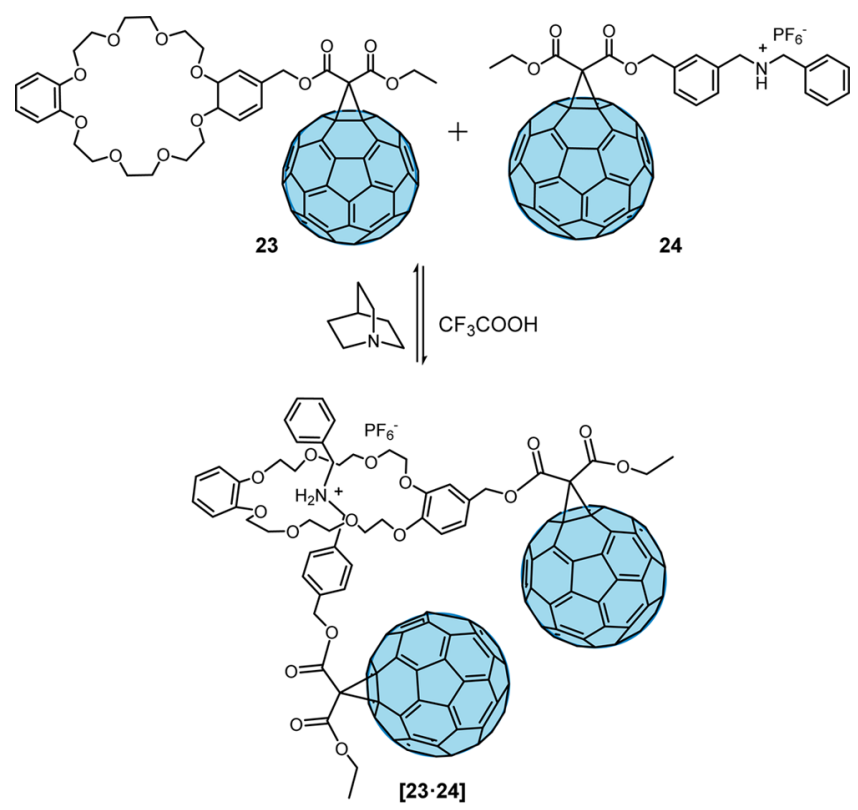

$\log K_{a}=3.0$

(rt, $\mathrm{CDCl}_{3}-\mathrm{CD}_{3} \mathrm{CN} 9: 1,{ }^{1} \mathrm{H}$ NMR)

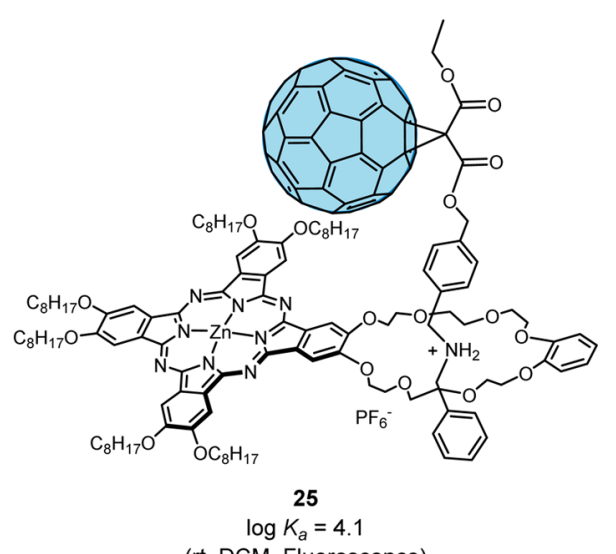

(rt, DCM, Fluorescence)

Figure 6. Molecular structures of the first [2] pseudorotaxane $\mathrm{Pc} / \mathrm{C}_{60}$ dyad.

supplementary recognition motif provided new $\pi-\pi$ and 78 charge-transfer interactions, leading to higher affinities. 79 Proximity effects of the crown ethers at different positions of 80 the host molecule and the possibility of having cooperative 81 effects between them explained the trend $14<15<13$.

Notably, stability of $\left[13 \cdot \mathrm{C}_{60}\right]$ could be tuned upon addition 83 of a potassium salt. An excess of it led to a decrease of the 84 nucleophility and to an increase on the rigidity of the crown 85 ether moiety, thus weakening the complex. Subsequent 86 addition of [18] crown- 6 captured the cation, reversing the 87 equilibrium and recovering the original complex (Scheme 1). ${ }^{22} 88 \mathrm{~s} 1$

More recently, our group designed molecular tweezer 16, 89 appended with two benzo[18]crown-6 ethers in an electron 90 donor 9,10-di(1,3-dithiol-2-ylidene)-9,10-dihydroanthracene 91 (exTTF) scaffold offering both geometric (concave-convex) 92 and electronic (donor-acceptor) complementarity (Figure 4). $93 \mathrm{f} 4$ The unique combination of these recognition elements led to 94 

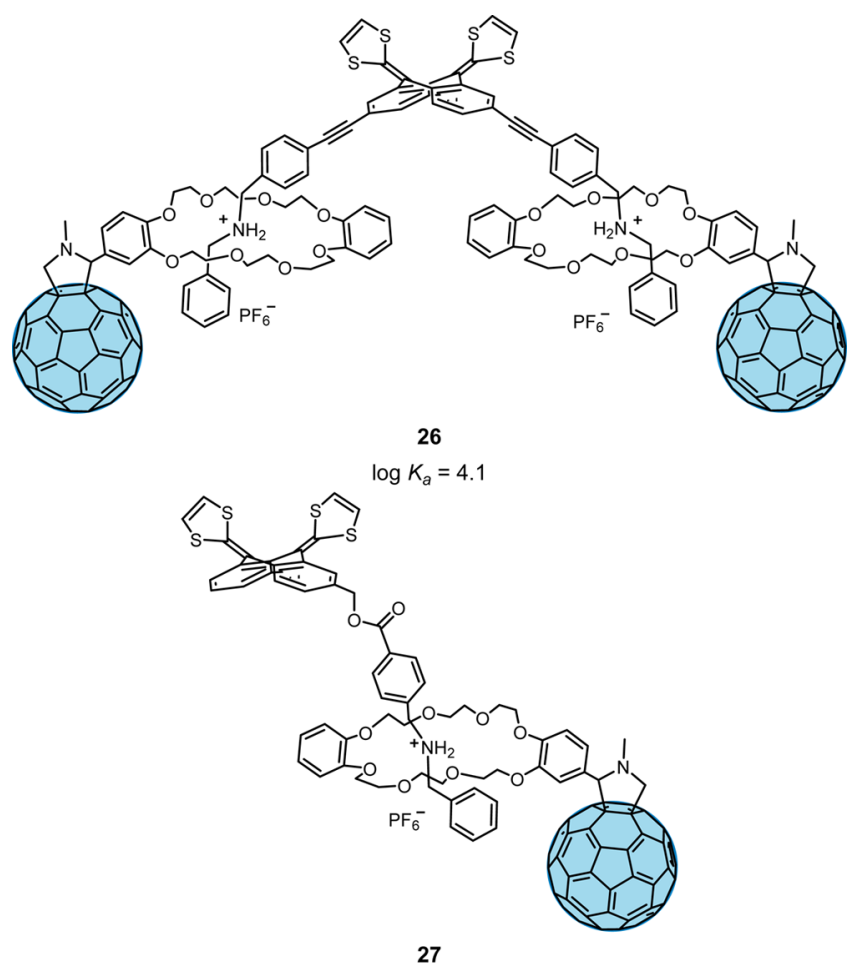

$\log K_{a}=3.3$

(rt, DCM/CH $\mathrm{CH}_{3} \mathrm{CN}$ 1:1, Fluorescence)

Figure 7. Stability constants of different DB[24]C8 fullerocrown ethers with exTTF-derived ammonium salts.

Scheme 4. Cooperativity between $\pi$-Stacking and Ammonium-Crown Ether Interactions Increased $K_{\mathrm{a}}$ by 2 Orders of Magnitude

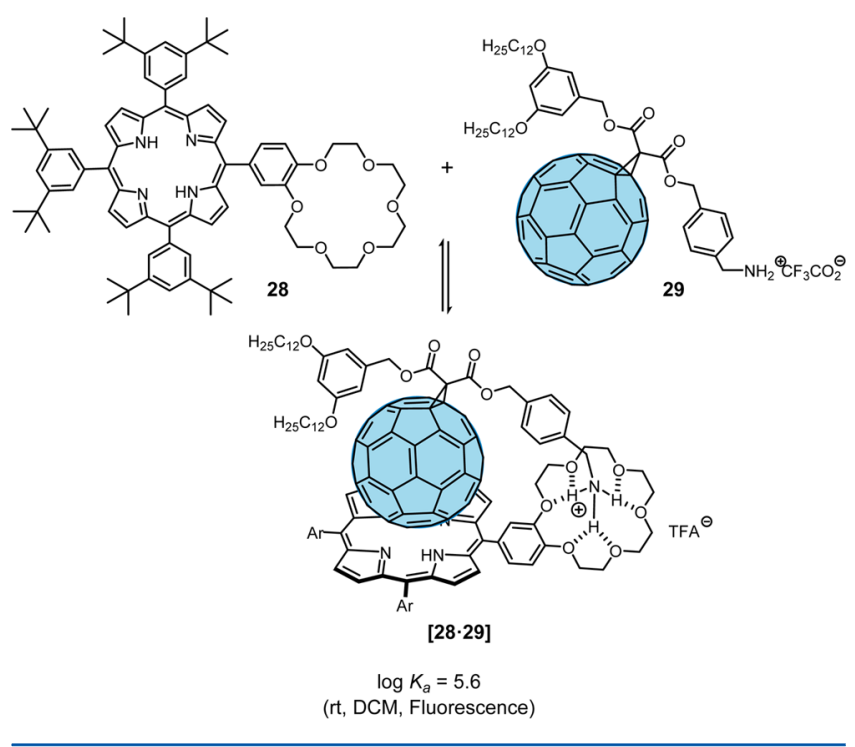

95 an extraordinarily high affinity toward fullerenes in spite of the 96 low degree of preorganization of the system. ${ }^{23}$

97 This result spurred our interest in unveiling the nature of 98 supramolecular crown ether $-\mathrm{C}_{60}$ affinity. As a result, we 99 performed a detailed evaluation of the supramolecular 100 interactions in receptors $\mathbf{1 7 - 2 2}$ (Scheme 2). The stability of 101 the resulting complexes varied more than 3 orders of magnitude 102 between 21, the receptor with the larger crown ethers, and 22,

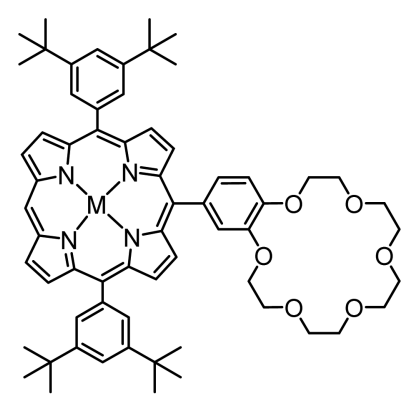

30-M

$(\mathrm{M}=2 \mathrm{H}, \mathrm{Co}, \mathrm{Ni}, \mathrm{Cu}, \mathrm{Zn})$

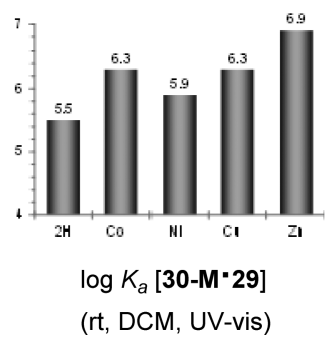

Figure 8. Host molecule $\mathbf{3 0 - \mathbf { M }}$ and its binding constants upon complexation with 29.

lacking them. Noteworthy, aza-crown ether derivatives $\mathbf{1 8}$ and 103 20 exhibited significantly smaller affinities than their oxygen- 104 bearing analogues $\mathbf{1 7}$ and $\mathbf{1 9}$ due to the less complementary 105 structure conferred by the additional flexibility of nitrogen 106 atoms (Figure 5, a-b). Additional electrochemical measure- $107 \mathrm{fs}$ ments, transient absorption spectroscopy, and theoretical 108 calculations were carried out, underpinning the experimental 109 findings and prompting to a synergetic interplay of donor- 110 acceptor, $\pi-\pi, \mathrm{n}-\pi$, and $\mathrm{CH} \cdots \pi$ interactions as the basis for the 111 affinity of our receptors toward $\mathrm{C}_{60}$ (Figure 5, c). ${ }^{24} 112$

Fullerene Derivatives. Whereas complexation of pristine 113 fullerenes allows us to maintain their electronic conjugation 114 and, thus, all of their singular properties, it has often been 115 chemically modified in order to increase the number of possible 116 recognition motifs as well as the complementarity and 117 preorganization of the host molecule and, therefore, the 118 stability of the supramolecular complexes obtained. ${ }^{25,26}$ This 119 becomes critical when working with crown ethers, which are 120 typically highly flexible and need to reorganize themselves at 121 the expense of an entropic cost. To overcome this, chemists 122 have introduced additional recognition motifs to the fullerenes, 123 typically ammonium ions, given their high degree of 124 directionality, selectivity, and large binding constants with 125 crown ethers. ${ }^{27}$

This approach was first used in 1999 by Diederich et al. to 127 combine fullerene derivatives 23 , embedded with a dibenzo-24- 128 crown-8, and fullerene malonate 24 , bearing a dibenzylammo- 129 nium salt (Scheme 3). Threading of the resulting pseudorotax- $130 \mathrm{~s} 3$ ane was $\mathrm{pH}$ dependent and reversible as supported by 131 fluorescence measurements. ${ }^{28}$

132

Soon, this strategy expanded into a series of molecularly 133 interlocked donor-acceptor complexes with well-defined 134 structures. The first one, developed in 2002 by Torres and 135 co-workers, consisted on phthalocyanine-fullerene dyad 25, 136 which exhibited a moderated binding constant in solution 137 (Figure 6). However, the distance between the donor and the $138 \mathrm{fo}$ acceptor moieties was too large to observe any electronic 139 
Scheme 5. (a) EM (Effective Molarity) of the System Obtained by Evaluating Each Supramolecular Interaction Separately Based on This Scheme. (b) Porphyrin-Fullerene Interaction Assessed by ${ }^{1} \mathrm{H}$ NMR Titration of 30-Zn with the Amino-Protected Methanofullerene 31 in $\mathrm{CDCl}_{3}$ at rt Yielding $K_{\mathrm{I}}$. (c) Stability of the Ammonium-crown-Ether Association, $K_{\mathrm{II}}$, Evaluated by ${ }^{1} \mathrm{H}$ NMR Titration of 29 with Reference Crown Ether $32^{a}$
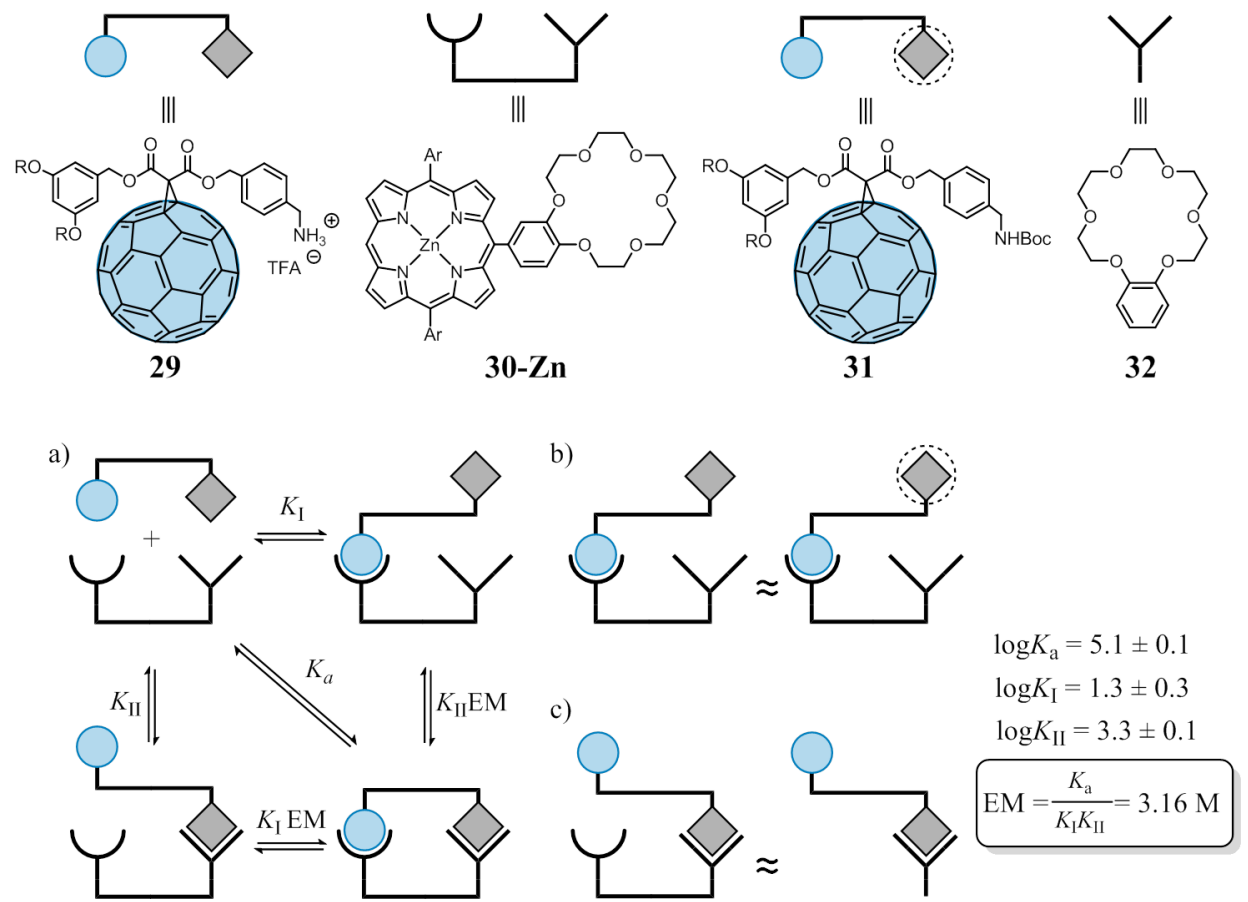

${ }^{a_{T}}$ The overall binding constant, $K_{a}$, was obtained by UV-vis titration of $30-\mathrm{Zn}$ with 29 in $\mathrm{CHCl}_{3}$ at rt.

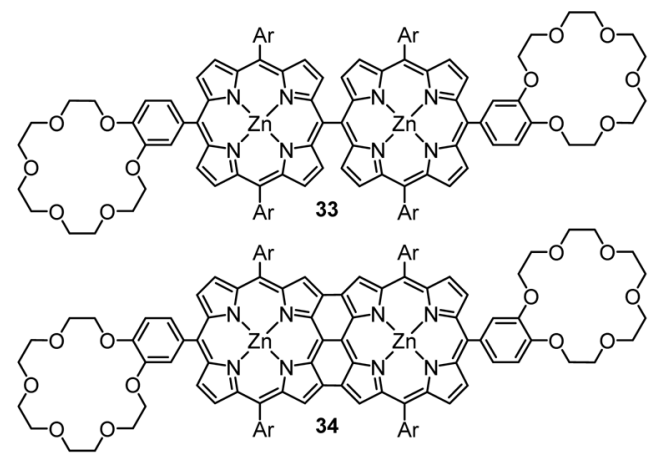

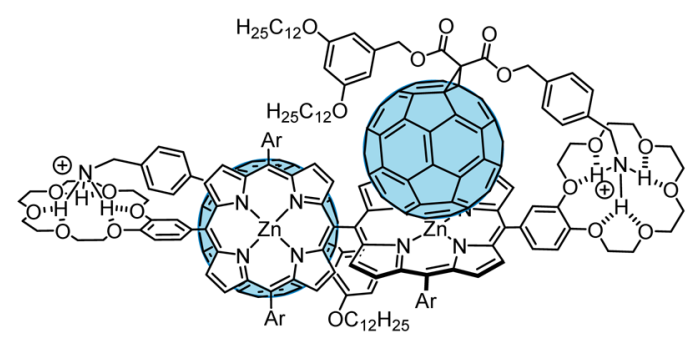

$\left[33 \cdot 29_{2}\right]$

$\log K_{1}=8.7$

$\log K_{2}=5.4$ $\alpha=0.0005$

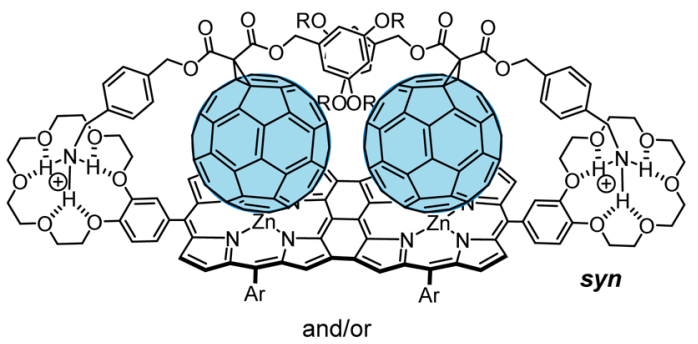

OR

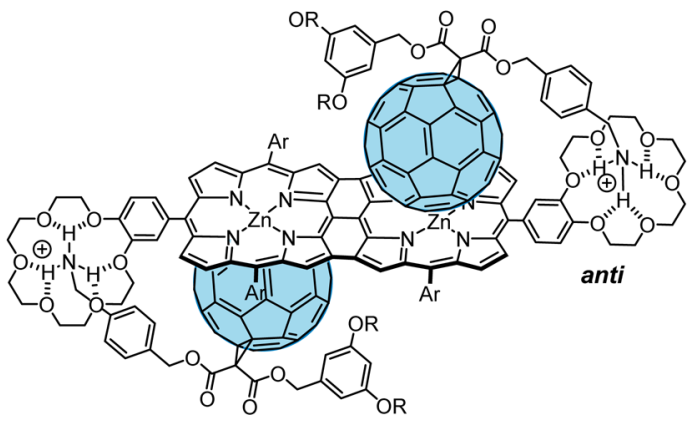

[34・292]

$\log K_{1}=6.8$

$\log K_{2}=5.4 \quad \alpha=0.04$

(rt, DCM, UV-vis)

Figure 9. Supramolecular complexes obtained from host molecules 33 and 34 with guest fullerene 29. 


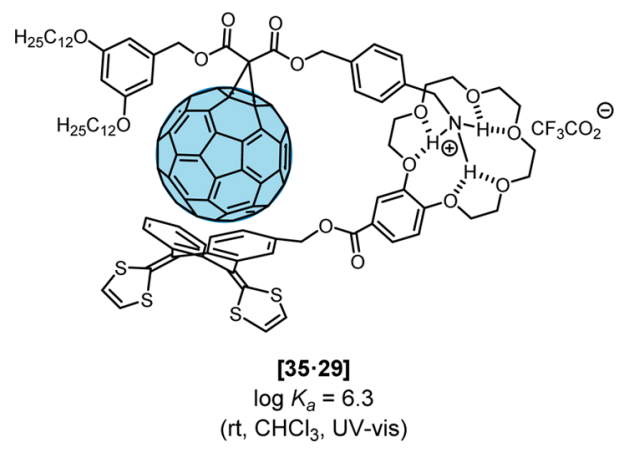

Figure 10. exTTF also offered $\pi-\pi$ interactions as an additional recognition motif while providing better geometrical complementarity.

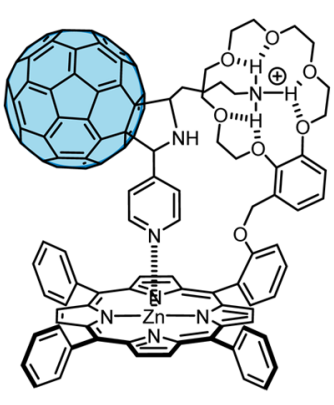

36

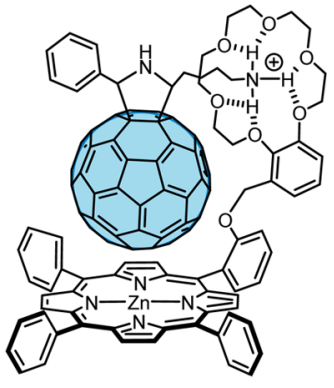

37 (rt, PhCN, Fluorescences)

Figure 11. Structure of complex 36, relying on axial coordination and of complex 37 , relying on $\pi$-stacking.

140 interaction on the ground state. ${ }^{29}$ Nevertheless, photochemical 141 investigation showed an effective intracomplex electron-transfer 142 mechanism on the excited state. ${ }^{30}$

143 Similar structures were obtained by combining fullerene 144 derivatives with other electroactive moieties such as triphenyl145 amine, $^{31}$ porphyrin, ${ }^{32,33}$ perylene, ${ }^{34}$ or terpyridine. ${ }^{35}$ In our 146 laboratory, we have also developed some analogous interlocked 147 systems by combining a dibenzo[24]crown-8-fullerene with a 148 series of exTTF-based secondary ammonium salts to obtain 149 complex $\mathbf{2 6}$ or the more flexible 27 (Figure 7). UV-vis and CV 150 measurements also revealed negligible electronic communica151 tions in the ground state, suggesting that both moieties are not 152 close enough. However, fluorescence analysis suggested an 153 electron transfer from the donor to the acceptor moiety in the 154 excited state. ${ }^{36}$

155 Given the limitations for obtaining electronic interactions in 156 the ground state with the pseudorotaxane approach, chemists 157 soon explored new designs with primary ammonium salts 158 offering stronger interactions. Following this approach, 159 Nierengarten and co-workers developed a cup-and-ball complex 160 conjugating meso-crown porphyrin $\mathbf{2 8}$ and fullerene malonate 16129 . Even though both porphyrin-fullerene and ammonium162 crown ether interactions are weak by themselves, ${ }^{37}$ their 163 cooperative interplay in [28.29] led to a dramatic increase of 164 the overall stability (Scheme 4 ). ${ }^{38}$

165 In light of this extraordinary result, the cooperative interplay 166 between the different noncovalent interactions was compre167 hensively analyzed. For this, 29 was complexed with a series of 168 new metalloporphyrin-crown ether receptors, 30-M, generat169 ing very stable complexes (Figure 8). Using a methanofullerene 170 was crucial in order to circumvent the low solubility of pristine fullerenes and, therefore, the strong entropic influence of 171 desolvation in the overall complexation stability. Spectroscopic, 172 electrochemical, and computational analyses demonstrated the 173 presence of electronic interactions in the ground state, which 174 suggested that the origin of $\pi-\pi$ interactions stems from 175 dispersion forces in free base porphyrins and from a 176 combination of electrostatic and dispersion interactions in 177 metalloporphyrins. The larger than expected stability of 30-Co 178 was explained on the basis of the strong interaction between 179 fullerenes and group 9 metals. Finally, the high value obtained 180 for the effective molarity (EM) of the system, a parameter 181 accounting for the easier formation of an intramolecular 182 reaction over its intermolecular analogous, proved the nice 183 complementarity of the receptor motifs in the [30-Zn·29] 184 (Scheme 5). ${ }^{39}$

The stability of these complexes led us to fuse $\mathbf{3 0 - Z n}$ into 186 porphyrin dimer 33, exhibiting two almost orthogonal 187 porphyrin moieties, and into porphyrin tape 34, where they 188 are fully conjugated (Figure 9). The tendency toward ring $189 \mathrm{fg}$ closing of $\mathbf{3 0 - Z n}$ enabled us to simplify the myriad of internal 190 micro equilibria leading to semicomplexed species into a two- 191 step process characterized by $K_{1}$ and $K_{2}$. Analysis of factor $\alpha 192$ evidenced a negative cooperativity in the complexation process; 193 i.e., binding of the first molecule of $\mathbf{2 9}$ led to a complex where it 194 was more difficult to bind a second equivalent. This fact was 195 justified by the decrease of the donating ability of the second 196 porphyrin moiety once the first fullerene unit has been added, a 197 phenomenon also observed in other porphyrin dyads. ${ }^{40} 198$

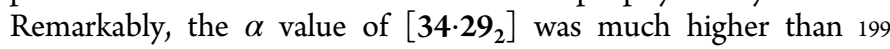
for $\left[33 \cdot 29_{2}\right]$, suggesting that this negative effect was partially 200 compensated by the stabilizing $\mathrm{C}_{60}-\mathrm{C}_{60}$ interactions taking 201 place in the more stable syn-disposition of $\left[\mathbf{3 4 \cdot 2 9 _ { 2 } ] . 3 9} 202\right.$

This cup-and-ball strategy has also been reproduced in other 203 supramolecular complexes. ${ }^{41,42}$ Among them, we developed 204 system 35 where the planar porphyrin moiety was replaced by 205 the concave surface of an exTTF molecule (Figure 10). The $206 \mathrm{f10}$ resulting binding constant was even larger than the one found 207 with free base porphyrin $\mathbf{2 8}$, thus highlighting the role of the 208 concave-convex complementarity. ${ }^{43}$

Alternatively, D'Souza and co-workers developed the so- 210 called "two-point" binding strategy, where axial coordination to 211 the metal atom with a pyridine moiety substituted the $\pi-\pi 212$ stacking between the porphyrin and the fullerene derivatives. 213 This approach enabled obtaining better control over the 214 distances and orientations of the building blocks. ${ }^{44}$ In addition, 215 the stronger axial coordination interaction contributed more 216 toward the overall stability of the resulting complexes as seen 217 when comparing 36 to 37 . This approach, however, hinders the 218 direct contact between the porphyrin and the [60]fullerene 219 (Figure 11). ${ }^{45}$ Interestingly, it was possible to switch between $220 \mathrm{f} 11$ intra- to intermolecular electron transfer in 37 by addition or 221 extraction of $\mathrm{K}^{+}$in a similar way than that observed for $[13 \cdot 222$ $\mathrm{C}_{60}$ ] (Scheme 1). ${ }^{46}$

More complex supramolecular ensembles constituted by 224 various fullerene derivatives or cofacial organization of 225 porphyrins or phtalocyanines have also been prepared. ${ }^{47-49} \quad 226$

\section{ENDOHEDRAL METALLOFULLERENES}

In spite of their structural resemblance, endohedral metal- 228 lofullerenes are intrinsically different from their empty 229 analogues, presenting unique properties such as metal-to-cage 230 electron transfer, larger absorptive coefficients in the visible 231 region of the electromagnetic spectrum, and a low HOMO- 232 
<smiles>C1CCNCCNCCNCCNCCNC1</smiles>

$\log K_{a}=5.7$<smiles>C1CNCCOCCOCCOCCOC1</smiles>

40

$\log K_{a}=4.5$
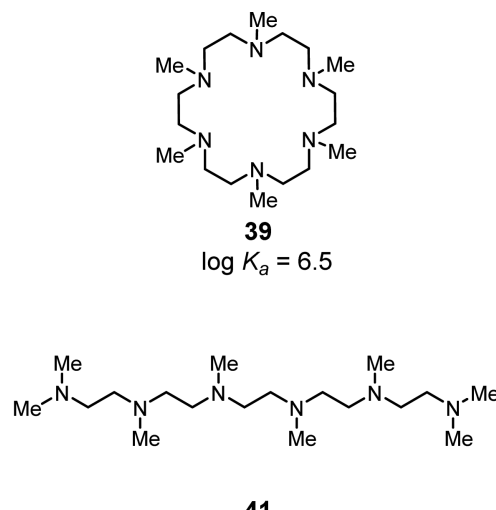

$\log K_{a}=4.5$

(rt, $\mathrm{PhNO}_{2}$, vis-NIR)

Figure 12. Receptors designed for the complexation of $\mathrm{La} @ \mathrm{C}_{82}$.

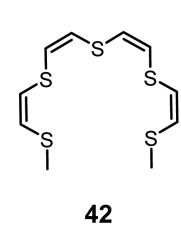

$\log K_{a}=1.7$

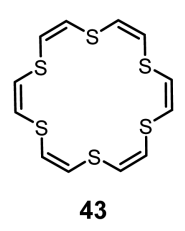

$\log K_{a}=2.0$

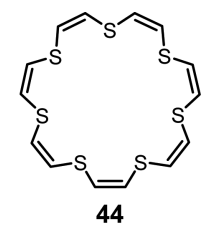

$\log K_{a}=2.1$

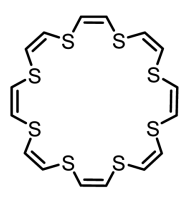

45

$\log K_{a}=2.0$

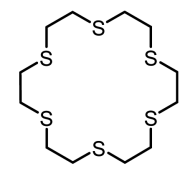

46

Too weak

(rt, $\mathrm{PhNO}_{2}$, vis-NIR)

Figure 13. Receptors designed for the formation of 1:1 complexes with La@C $\mathrm{C}_{82}$.

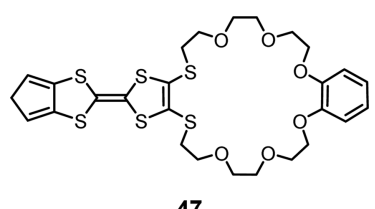

47

$\log K_{a}=6.3$

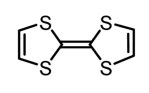

49

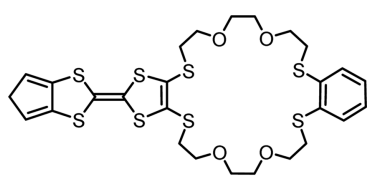

48

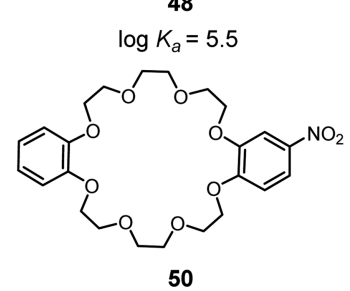

Figure 14. MPTTF derivatives designed as receptors for $\mathrm{Li}^{+} @ \mathrm{C}_{60}$ and reference compounds TTF and $4^{\prime}$-nitrobenzene $[24]$ crown- 8 ether.

233 LUMO energy gap. ${ }^{10,50}$ Unfortunately, their scarce availability 234 has largely hindered their use up to date.

235 In this context, the affinity of $\mathrm{La}_{2} \mathrm{C}_{82}$ toward nitrogen236 containing solvents, enabling its preferential extraction from 237 raw soot, led to the study of its 1:1 supramolecular complexes 238 with azacrown ethers $38-40$ and polyamine 41 (Figure 12). As 239 in previous cases, the affinity increased with the number of 240 heteroatoms, whereas the lower affinity of acyclic polyamine 41

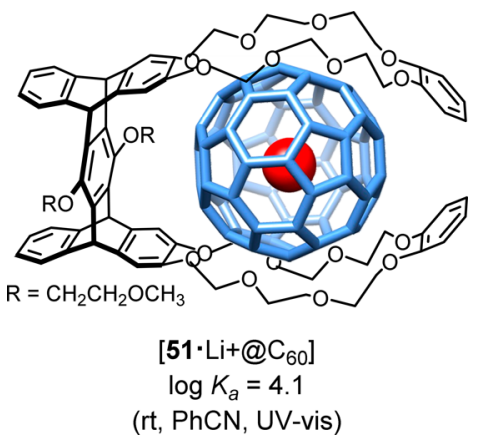

Figure 15. Molecular representation of the complex formed between the PCBE host and the $\mathrm{Li}^{+} @ \mathrm{C}_{60}$ guest.

in comparison to 39 pointed to the presence of a macrocycle 241 effect. Further electrochemical studies revealed that crown 242 ethers were acting as donor moieties in electron-transfer 243 processes. $^{51-55} 244$

In order to gain further information on the structure, 245 Akasaka and co-workers developed a new series of sulfur 246 derivatives 42-46 including unsaturated crowns 43-45, known 247 to exhibit a rigid structure with the sulfur atoms forced toward 248 the inside of the ring (Figure 13). Vis-NIR spectroscopy and $249 \mathrm{f} 13$ electrochemical studies supported that $\mathrm{La} @ \mathrm{C}_{82}$ formed weak 250 complexes with 43-46 via an electron-transfer process where 251 the metallofullerene was reduced to its anion form. Whereas 252 thia-crown ether $\mathbf{4 4}$ exhibited the largest binding constant, due 253 to its best complementarity, 46 did not exhibit effective 254 complexation, thus highlighting the importance of the olefinic 255 moiety. $^{56}$

256

Following these examples, Jeppesen, Fukuzumi, and co- 257 workers obtained strong complexation between $\mathrm{Li}^{+} @ \mathrm{C}_{60}$ and 258 crown ether functionalized monopyrrolotetrathiafulavelene 259 (MPTTF) derivatives 47 and 48 (Figure 14). Binding $260 \mathrm{f} 14$ constants obtained were much higher than those of their 261 crown size related complexes $\mathbf{1 1} \cdot \mathrm{C}_{\mathbf{6 0}}$ and $\mathbf{1 2} \cdot \mathrm{C}_{\mathbf{6 0}}$, pinpointing 262 the importance of electrostatic interactions with the endohedral 263 metal. In order to obtain better insights, $\mathrm{Li}^{+} @ \mathrm{C}_{60}$ was treated 264 separately with TTF and 4 '-nitrobenzene[24]crown-8 ether, 265 observing interaction only with the crown ether. In addition, as 266 no charge-transfer band was observed for 47. $\mathrm{Li}^{+} @ \mathrm{C}_{60}, 267$ complexation was proposed to occur through the interactions 268 with the crown ethers, something supported by DFT 269 calculations. Theoretical calculations on $\mathbf{4 8}$ evidenced that the 270 larger size of the sulfur atoms took further away the fullerene 271 from the crown ether than in 47, therefore explaining its lower 272 stability. $^{57}$

In sight of these results, a new receptor for $\mathrm{Li}^{+} @ \mathrm{C}_{60} 274$ consisting in a rigid pentiptycene-based bis(crown ether) host 275 (PBCE), 51, was developed (Figure 15). The electron donor $276 \mathrm{f} 15$ character of the scaffold led to a photoinduced electron-transfer 277 process through a rigid distance in the complex. Interestingly, 278 the assisting role of the $\mathrm{Li}^{+}$ion inside the cage in the 279 supramolecular recognition is clear when considering that 280 complexation was not observed with $\mathrm{C}_{60}{ }^{58}$

\section{CARBON NANOTUBES}

In contrast to the rich supramolecular chemistry of fullerenes, 283 carbon nanotubes (CNT) have been considerably less explored 284 due to the difficulty in obtaining homogeneous and well- 285 defined structures. This is a pressing problem considering that 286 the outstanding electronic and mechanical properties of single 287 
Scheme 6. Synthetic Scheme for the SWCNT/Crown Ether Complex 54

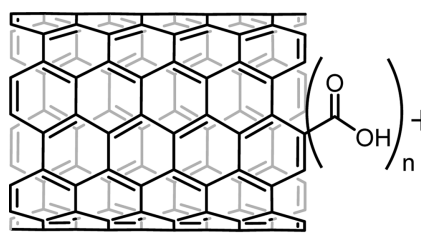

52

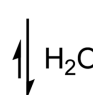

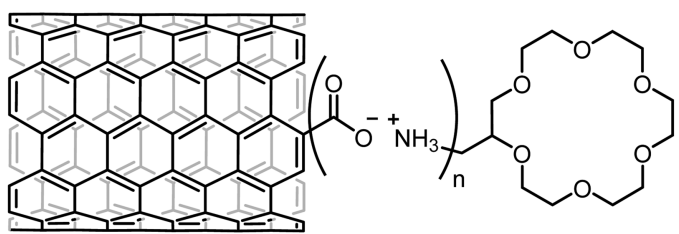

54
288 walled CNT (SWCNT) require their effective dispersion, 289 solubilization, and separation after overcoming large van der 290 Waals forces between adjacent tubes. ${ }^{59}$ Whereas solubilization 291 has mainly been achieved by covalent modification of the 292 SWCNT, ${ }^{60-63}$ this approach implies disturbing their $\pi$ system 293 and electronic properties. As a result, noncovalent methods 294 have emerged as a useful alternative.

295 In this regard, Wong and co-workers have solubilized 296 oxidized carbon nanotubes, 52, by conjugating the carboxylic 297 groups present at their ends or oxidized defect sites with 2298 aminomethyl-18-crown-6 ether, 53, achieving high concen299 trations of complex $\mathbf{5 4}$ in different organic solvents. Given the 300 mild reaction conditions and that the adduct does not appear to 301 form in the presence of standard carbodiimide linker reagents, 302 this interaction arises most likely from an $\mathrm{R}-\mathrm{COO}^{-+} \mathrm{H}_{3} \mathrm{~N}-\mathrm{R}$ 303 ionic interaction between the carboxylate anions and the 304 ammonium group and not through a covalent bond (Scheme $3056) .{ }^{64,65}$

306 An alternative strategy to disperse SWCNT consists in 307 forming their respective polyelectrolytes, where nanotubes 308 become negatively charged by reduction and subsequently 309 repelled by Coulombic interactions upon addition of polar 310 aprotic solvents. Following this approach, Marti and co-workers 311 studied the impact of complexing these SWCNT polyelec312 trolytes with $[18]$ crown- 6 , finding that trapping the potassium 313 cation shielded their charge from their counterions, preventing 314 their combination and increasing the repulsions between 315 nanotubes (Scheme 7). The resulting solubility of the 316 SWCNT was largely increased, exceeding all previously 317 reported values. ${ }^{66,67}$
Supramolecular interactions have also been used to direct the 318 self-assembly of gold nanowire over CNTs. For this, Sainsbury 319 et al. combined dibenzo[24]crown-8-modified gold nano- 320 particles, 55, with dibenzylammonium cation-modified multi- 321 walled carbon nanotube (MWCNT), 56 (Figure 16). As $322 \mathrm{fl} 6$ evidenced by several control experiments, the driving force for 323 the formation of the nanowire was the complexation of the 324 MWCNTs with the crown ether moieties to form a surface- 325 confined pseudorotaxane. ${ }^{68}$

326

Planar pyrene derivatives have also been used as supra- 327 molecular anchors providing a versatile platform for obtaining 328 SWCNT hybrids where the main interaction is $\pi$-stacking, ${ }^{69} 329$ which not only aids in the exfoliation of the nanotubes but also 330 enables linking different molecules on its surface. This approach 331 was used by D'Souza and co-workers to build SWCNT donor- 332 acceptor hybrids were electron transfer occurred in the excited 333 state from a meso-crown porphyrin subunit to the SWCNT in 334 $57^{70}$ or from the SWCNT to a more acceptor fullerene 335 derivative in $\mathbf{5 8}$ (Scheme 8). ${ }^{71}$

Carbon Nanohorns. Carbon nanohorns (CNHs) are 337 topologically related to carbon nanotubes as they could be 338 considered a capped version of them with a highly constrained 339 end. However, they are easier to obtain pure due to their metal- 340 free synthesis. In spite of this, their supramolecular properties 341 remain largely unexplored. Some remarkable exceptions are the 342 supramolecular dyads developed by Vizuete et al., which 343 demonstrated that $\mathrm{CNHs}$ can act as acceptor systems when 344 confronted to strong electron-donating molecules such as 345 porphyrins $(\mathbf{5 9})^{72}$ or behave as donor systems when combined 346 with fullerene derivatives (60). Transient absorption spectros- 347 copy allowed to determine that, upon excitation, the radical 348 cation of the porphyrin moiety in $\mathbf{5 9}$ or the radical anion of the 349 $\mathrm{C}_{60}$ moiety in $\mathbf{6 0}$ are formed, which implies that the $\mathrm{CNHs}$ can 350 both accept an electron from the donor porphyrin or give an 351 electron to the fullerene unit. As in previous cases, the 352 ammonium-crown ether interaction was critical in obtaining 353 stable complexes (Scheme 9). ${ }^{73}$

\section{GRAPHENE}

355

Surprisingly, whereas all the previous nanostructures can be 356 seen as derivatives from graphene, the supramolecular 357 combination between graphene and crown ethers has not 358 been properly addressed so far. This is striking when 359 considering that many of the previous examples could be 360 taken as benchmarks, that there is already a number of covalent 361 conjugates $^{74,75}$ and that crown ethers have even been 362 embedded within the graphene structure. ${ }^{76}$

A notable exception was developed by Wei et al. when 364 [18] crown- 6 adsorbed on the surface of graphene was used as a 365 molecular anchor for carbon dots (CDs). Interestingly, 366 fluorescence of the CDs was effectively quenched by addition 367 of a solution containing the crown ether-graphene conjugate 368

Scheme 7. Scheme of the Crown-Ether-Assisted Dissolution of SWCNT Polyelectrolytes
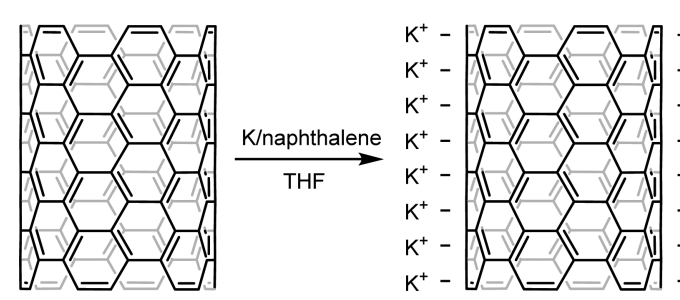
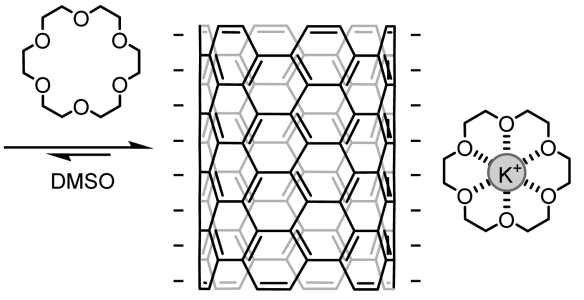


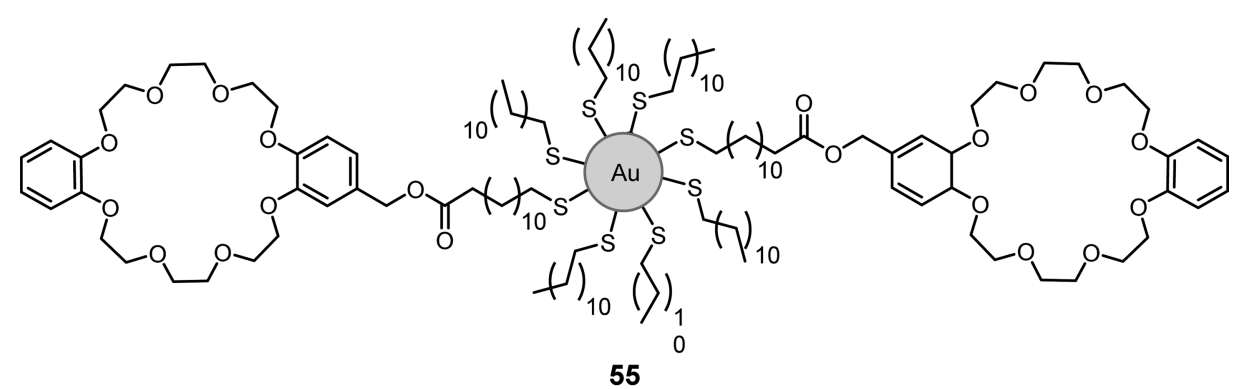

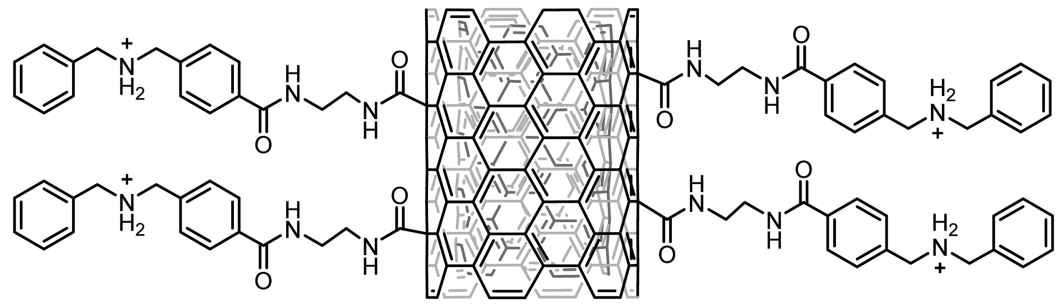

56

Figure 16. Building blocks used for the self-assembly of a golden nanowire over CNTs.

Scheme 8. Chemical Structure of SWCNT-Pyr- $\mathrm{NH}_{3}{ }^{+}-$ Crown-Porphyrin Nanohybrid 57 and of SWCNT-Pyr$\mathrm{NH}_{3}{ }^{+}-$Crown $-\mathrm{C}_{60}$ Conjugate 58

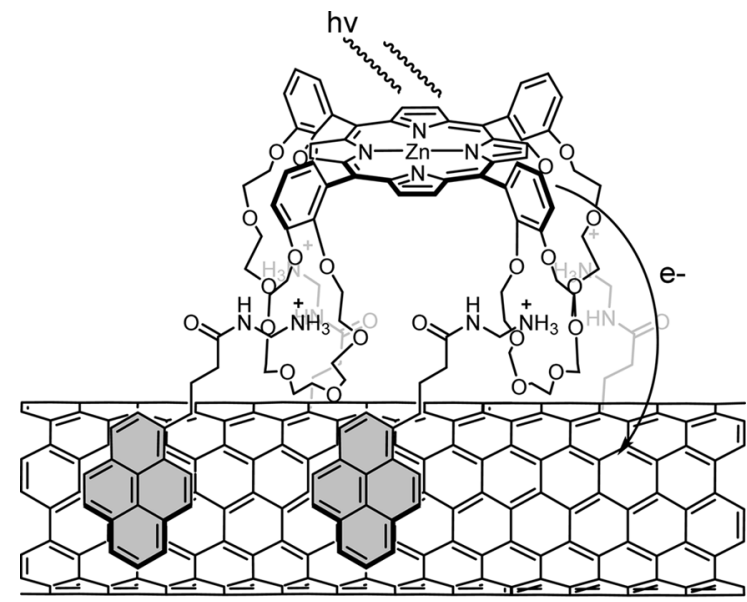

57

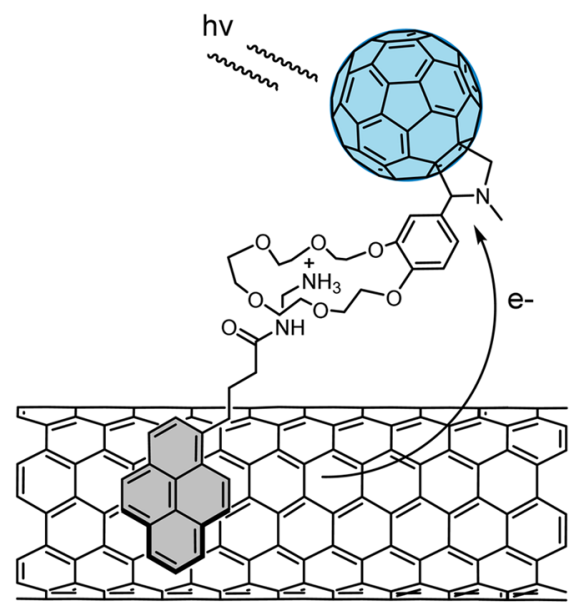

58 through a FRET process. Subsequent addition of a potassium 369 salt would decomplex that supramolecular system due to the 370 stronger affinity of [18]crown-6 toward the potassium salt, thus 371 recovering the fluorescence of the $\mathrm{CD}$. In this manner, this 372 system could be used as an effective all-carbon sensor for 373 potassium determination (Scheme 10). ${ }^{77}$

\section{SUMMARY AND OUTLOOK}

375

Along this synopsis, it has been evidenced the extraordinary 376 ability of crown ethers to form supramolecular complexes with 377 different carbon nanostructures and the impact of changing 378 their size and composition in modulating the $\pi-\pi, \mathrm{n}-\pi, 379$ $\mathrm{CH}-\pi$, dispersion forces, and/or charge-transfer interactions 380 governing this recognition. Furthermore, adding different 381 substituents can significantly modify the efficiency of the 382 complexation process by adding additional recognition motifs 383 which broaden the scope of complexation.

Fullerenes have been, by far, the most widely studied systems 385 for their supramolecular interaction with crown ethers provided 386 their well-defined geometry and electronic properties either in 387 their pristine form or in the wide variety of derivatives prepared 388 along the last three decades. ${ }^{78-80}$ Interestingly, these studies 389 have been used as a benchmark for further carbon 390 nanostructures such as CNT and graphene.

391

Crown ethers have also been used for complexing supra- 392 molecularly CNT, and to a lesser extent $\mathrm{CNH}$ and graphene, in 393 the search for better solubility and exfoliation properties as well 394 as for their electronic modification by means of photo- and/or 395 electroactive molecules, which represents an easy methodology 396 for $\mathrm{n}$ - and p-doping of these materials. As with fullerenes, 397 crown ethers have provided a useful and versatile alternative for 398 the noncovalent chemical modification of these carbon 399 nanostructures, taking advantage of the rich diversity of weak 400 forces stemming from these complementary molecular systems. 401

\section{AUTHOR INFORMATION}

*E-mail: nazmar@ucm.es, http://www.nazariomartingroup. 404 $\mathrm{com} /$. 
Scheme 9. Electronic Transfer in a Series of DonorAcceptor Conjugates Where the CNH Can Act as a Donor or as an Acceptor

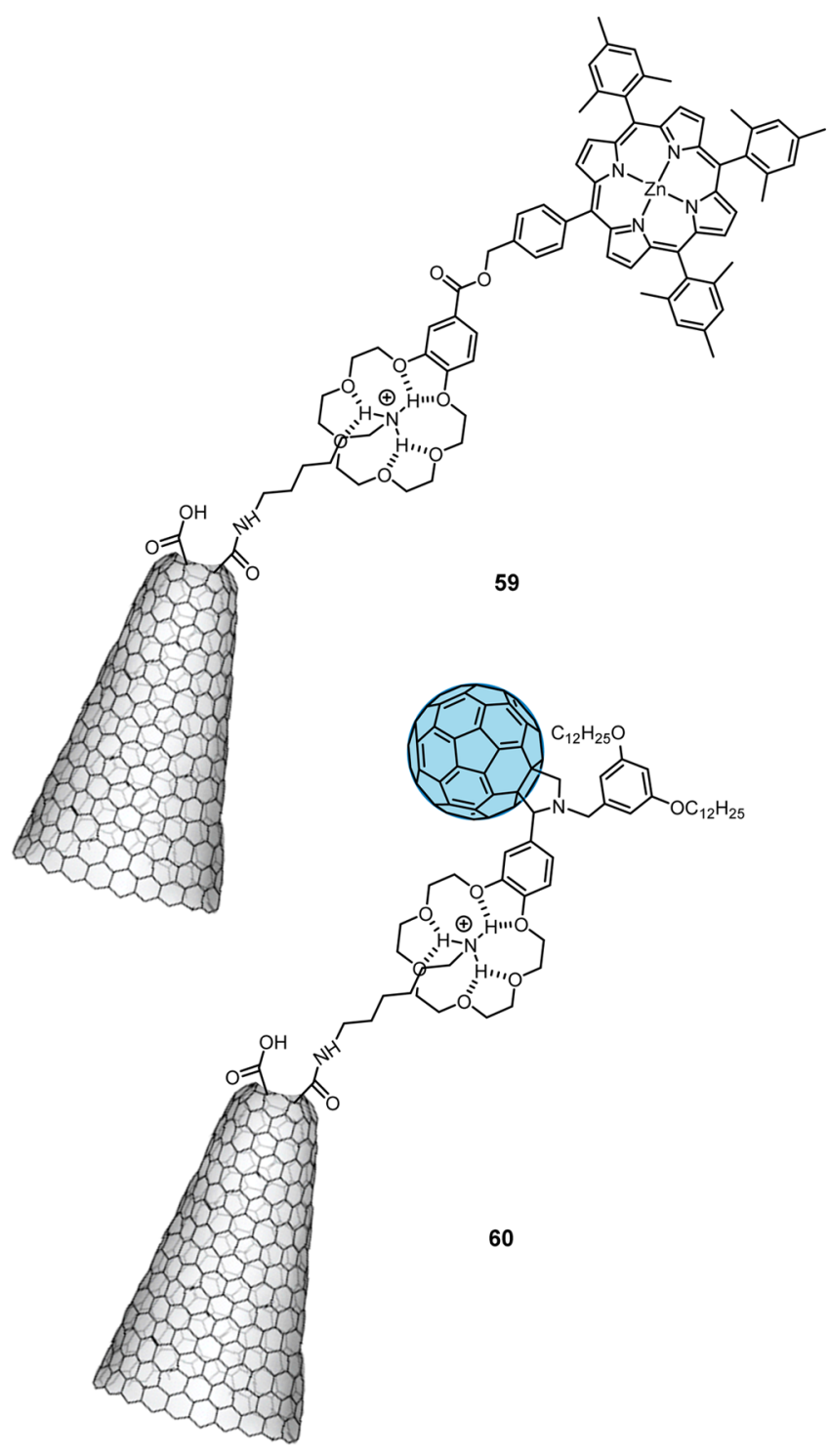

406 ORCID

407 Nazario Martín: 0000-0002-5355-1477

408 Notes

409 The authors declare no competing financial interest.

410 Biographies

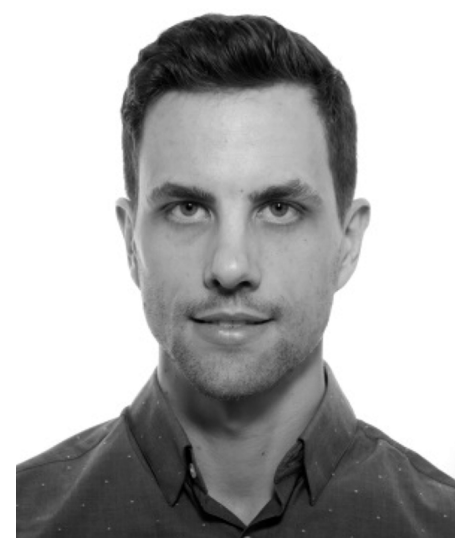

Scheme 10. Proposed Mechanism for the Graphene-Based Metal Sensor
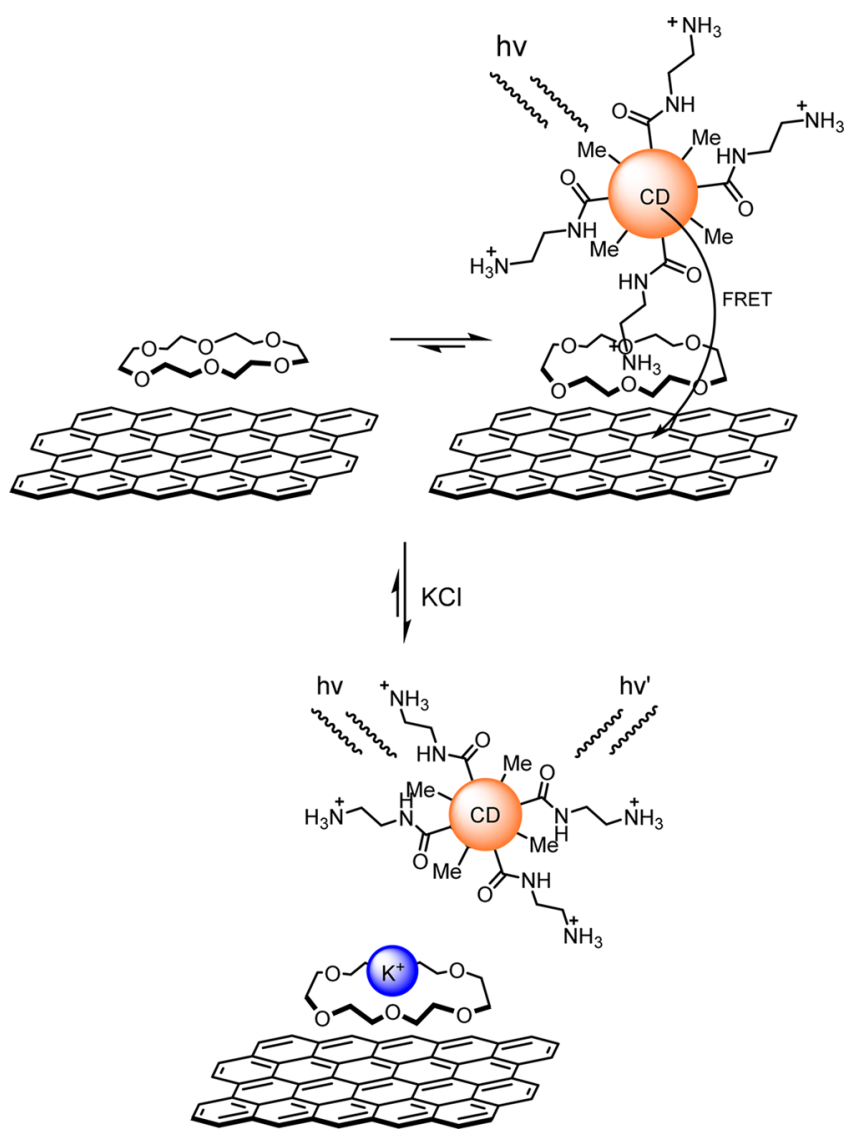

Dr. Luis Moreira obtained a joint degree in chemistry from the 411 Universidad Autónoma de Madrid and the École Européene de 412 Chimie, Polymères et Matériaux of Strasbourg in 2009. In 2013, he 413 obtained a Ph.D. focused on the construction of supramolecular crown 414 ether containing donor-acceptor ensembles under the supervision of 415 Prof. Nazario Martín and Dr. Jean-François Nierengarten. In 2015, he 416 obtained an MBA from the IE Business School and started working as 417 a scientific advisor for an FMCG international company. 418

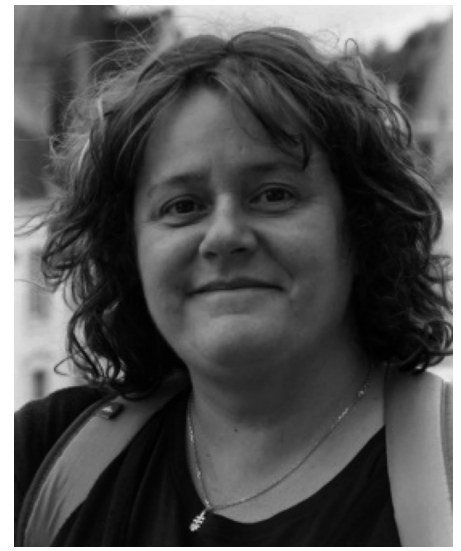

Dr. Beatriz M. Illescas graduated in Organic Chemistry from 419 Universidad Complutense de Madrid in 1992 and obtained a Ph.D. 420 under the direction of Profs. Carlos Seoane and Nazario Martín in 421 1998. After a postdoctoral fellowship with JANSSEN-CILAG, S.A., she 422 joined the faculty and is currently Professor of Chemistry at the UCM. 423 Her research interests focus mainly on the chemical modification of 424 carbon nanostructures. 425 


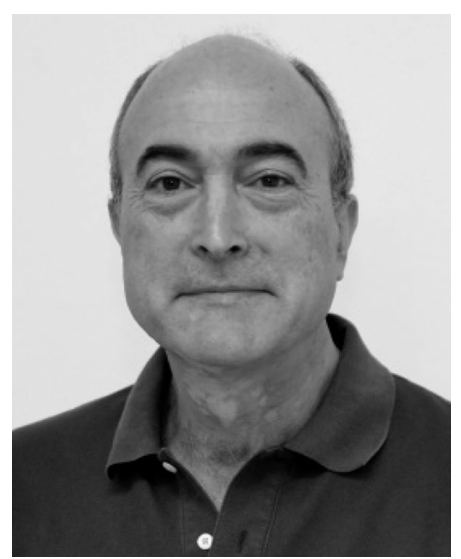

426 Nazario Martín, FRSC, is a full professor at the University 427 Complutense of Madrid and vice-director of IMDEA-Nanoscience 428 Institute. He received a Dr. h.c. from La Havana and Castilla La 429 Mancha Universities, and his research interests are focused on 430 molecular and supramolecular chemistry of carbon nanostructures in 431 the context of chirality, electron transfer, photovoltaic applications, 432 and nanoscience. He has published over 500 papers and supervised 34 433 theses. He is a member of the IAB of several international journals and 434 Editor-in-Chief of The Journal of Materials Chemistry ( $A, B$ and $C)$. He 435 is currently the President of the Confederation of Scientific Societies of 436 Spain (COSCE). He has the "Advanced Grant" of the European 437 Research Council (ERC) entitled "Chirallcarbon".

\section{ACKNOWLEDGMENTS}

439 Financial support by the European Research Council (ERC440 320441-Chiralcarbon), the Ministerio de Economía y Com441 petitividad (MINECO) of Spain (project CTQ2014-52045-R), 442 the Comunidad Autónoma de Madrid (PHOTOCARBON 443 project S2013/MIT-2841), and the European Commission 444 (EC) FP/ITN "MOLESCO" (Project No. 606728) is 445 appreciated. L.M. thanks the Obra Social "la Caixa" for a 446 postgraduate fellowship.

447 REFERENCES

448 (1) Pedersen, C. J. J. Am. Chem. Soc. 1967, 89, 7017.

449 (2) Dietrich, B.; Lehn, J. M.; Sauvage, J. P. Tetrahedron Lett. 1969, 10, 4502885.

451 (3) Cram, D. J.; Kaneda, T.; Helgeson, R. C.; Lein, G. M. J. Am. 452 Chem. Soc. 1979, 101, 6752.

453 (4) Cragg, P. J.; Vahora, R. In Supramolecular Chemistry; John Wiley 454 \& Sons, Ltd., 2012.

455 (5) Kroto, H. W.; Heath, J. R.; O’Brien, S. C.; Curl, R. F.; Smalley, R. 456 E. Nature 1985, 318, 162.

457 (6) Iijima, S. Nature 1991, 354, 56.

458 (7) Iijima, S.; Ichihashi, T. Nature 1993, 363, 603.

459 (8) Bethune, D. S.; Klang, C. H.; de Vries, M. S.; Gorman, G.; Savoy, 460 R.; Vazquez, J.; Beyers, R. Nature 1993, 363, 605.

461 (9) Novoselov, K. S.; Geim, A. K.; Morozov, S. V.; Jiang, D.; Zhang, 462 Y.; Dubonos, S. V.; Grigorieva, I. V.; Firsov, A. A. Science 2004, 306, 463666.

464 (10) Delgado, J. L.; Herranz, M. A.; Martín, N. J. Mater. Chem. 2008, 46518,1417

466 (11) Hiroshi, I.; Kiyoshi, H.; Tsuyoshi, A.; Masanori, A.; Seiji, T.; 467 Tadashi, O.; Masahiro, S.; Yoshiteru, S. Chem. Phys. Lett. 1996, 263, 468545.

469 (12) Xie, Q.; Pérez-Cordero, E.; Echegoyen, L. J. Am. Chem. Soc. 470 1992, 114, 3978.

471 (13) Ajie, H.; Alvarez, M. M.; Anz, S. J.; Beck, R. D.; Diederich, F.; 472 Fostiropoulos, K.; Huffman, D. R.; Kraetschmer, W.; Rubin, Y.;
Schriver, K. E.; Sensharma, D.; Whetten, R. L. J. Phys. Chem. 1990, 94, 473 8630.

(14) Guldi, D. M.; Prato, M. Acc. Chem. Res. 2000, 33, 695.

(15) Castellanos, S.; Vieira, A. A.; Illescas, B. M.; Sacchetti, V.; 476 Schubert, C.; Moreno, J.; Guldi, D. M.; Hecht, S.; Martín, N. Angew. 477 Chem., Int. Ed. 2013, 52, 13985.

(16) Effing, J.; Jonas, U.; Jullien, L.; Plesnivy, T.; Ringsdorf, H.; 479 Diederich, F.; Thilgen, C.; Weinstein, D. Angew. Chem., Int. Ed. Engl. 480 1992, 31, 1599.

(17) Bhattacharya, S.; Sharma, A.; Nayak, S. K.; Chattopadhyay, S.; 482 Mukherjee, A. K. J. Phys. Chem. B 2003, 107, 4213.

(18) Saha, A.; Nayak, S. K.; Chottopadhyay, S.; Mukherjee, A. K. J. 484 Phys. Chem. B 2003, 107, 11889.

(19) Datta, K.; Banerjee, M.; Mukherjee, A. K. J. Phys. Chem. B 2004, 486 $108,16100$.

(20) Bhattacharya, S.; Sharma, A.; Nayak, S. K.; Mukherjee, A. K. 488 Spectrochim. Acta, Part A 2002, 58, 2841.

(21) Liu, Y.; Han, J.-R.; Zhao, Y.-L.; Zhang, H.-Y.; Duan, Z.-Y. J. 490 Inclusion Phenom. Mol. Recognit. Chem. 2005, 51, 191.

(22) D’Souza, F.; Chitta, R.; Gadde, S.; Zandler, M. E.; McCarty, A. 492 L.; Sandanayaka, A. S. D.; Araki, Y.; Ito, O. J. Phys. Chem. A 2006, 110, 493 4338.

(23) Grimm, B.; Santos, J.; Illescas, B. M.; Muñoz, A.; Guldi, D. M.; 495 Martín, N. J. Am. Chem. Soc. 2010, 132, 17387.

(24) Moreira, L.; Calbo, J.; Krick Calderon, R. M.; Santos, J.; Illescas, 497 B. M.; Arago, J.; Nierengarten, J.-F.; Guldi, D. M.; Ortí, E.; Martín, N. 498 Chem. Sci. 2015, 6, 4426.

(25) Cram, D. J.; Cram, J. M. Container Molecules and Their Guests; 500 Royal Society of Chemistry, 1994.

(26) Wittenberg, J. B.; Isaacs, L. In Supramolecular Chemistry; John 502 Wiley \& Sons, Ltd., 2012.

(27) Rüdiger, V.; Schneider, H.-J.; Solov'ev, V. P.; Kazachenko, V. P.; 504 Raevsky, O. A. Eur. J. Org. Chem. 1999, 1999, 1847.

(28) Diederich, F.; Echegoyen, L.; Gómez-López, M.; Kessinger, R.; 506 Stoddart, J. F. J. Chem. Soc., Perkin Trans. 2 1999, 1577.

(29) Martínez-Díaz, M. V.; Fender, N. S.; Rodríguez-Morgade, M. S.; 508 Gómez-López, M.; Diederich, F.; Echegoyen, L.; Stoddart, J. F.; 509 Torres, T. J. Mater. Chem. 2002, 12, 2095.

(30) Guldi, D. M.; Ramey, J.; Martínez-Díaz, M. V.; Escosura, A. d. 1.; 511 Torres, T.; Da Ros, T.; Prato, M. Chem. Commun. 2002, 2774.

(31) Sandanayaka, A. S. D.; Sasabe, H.; Araki, Y.; Furusho, Y.; Ito, O.; 513 Takata, T. J. Phys. Chem. A 2004, 108, 5145.

(32) Maes, M.; Sasabe, H.; Kihara, N.; Araki, Y.; Furusho, Y.; 515 Mizuno, K.; Takata, T.; Ito, O. J. Porphyrins Phthalocyanines 2005, 09, 516 724.

(33) Dordevic, L.; Marangoni, T.; De Leo, F.; Papagiannouli, I.; 518 Aloukos, P.; Couris, S.; Pavoni, E.; Monti, F.; Armaroli, N.; Prato, M.; 519 Bonifazi, D. Phys. Chem. Chem. Phys. 2016, 18, 11858.

(34) Yao, H.; Zhang, H.; Han, M.; Ding, Z.; Zhang, Z.; Liu, Y. Sci. 521 China: Chem. 2010, 53, 1982.

(35) Ding, Z.-J.; Zhang, Y.-M.; Teng, X.; Liu, Y. J. Org. Chem. 2011, 523 76, 1910.

(36) Illescas, B. M.; Santos, J.; Díaz, M. C.; Martín, N.; Atienza, C. 525 M.; Guldi, D. M. Eur. J. Org. Chem. 2007, 2007, 5027.

(37) Solladié, N.; Walther, M. E.; Herschbach, H.; Leize, E.; 527 Dorsselaer, A. V.; Duarte, T. M. F.; Nierengarten, J.-F. Tetrahedron 528 2006, 62, 1979.

(38) Solladié, N.; Walther, M. E.; Gross, M.; Duarte, T. M. F.; 530 Bourgogne, C.; Nierengarten, J.-F. Chem. Commun. 2003, 2412. (39) Moreira, L.; Calbo, J.; Illescas, B. M.; Aragó, J.; Nierengarten, I.; 532 Delavaux-Nicot, B.; Ortí, E.; Martín, N.; Nierengarten, J.-F. Angew. 533 Chem., Int. Ed. 2015, 54, 1255.

(40) Sato, H.; Tashiro, K.; Shinmori, H.; Osuka, A.; Murata, Y.; 535 Komatsu, K.; Aida, T. J. Am. Chem. Soc. 2005, 127, 13086.

(41) Elhabiri, M.; Trabolsi, A.; Cardinali, F.; Hahn, U.; Albrecht- 537 Gary, A.-M.; Nierengarten, J.-F. Chem. - Eur. J. 2005, 11, 4793.

(42) Nierengarten, J.-F.; Hahn, U.; Trabolsi, A.; Herschbach, H.; 539 Cardinali, F.; Elhabiri, M.; Leize, E.; Van Dorsselaer, A.; Albrecht- 540 Gary, A.-M. Chem. - Eur. J. 2006, 12, 3365.

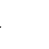

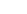
(n)

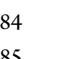


542 (43) Santos, J.; Grimm, B.; Illescas, B. M.; Guldi, D. M.; Martín, N. 543 Chem. Commun. 2008, 5993.

544 (44) D’Souza, F.; Chitta, R.; Gadde, S.; Zandler, M. E.; Sandanayaka, 545 A. S. D.; Araki, Y.; Ito, O. Chem. Commun. 2005, 1279.

546 (45) D’Souza, F.; Chitta, R.; Gadde, S.; Zandler, M. E.; McCarty, A. 547 L.; Sandanayaka, A. S. D.; Araki, Y.; Ito, O. Chem. - Eur. J. 2005, 11, 5484416.

549 (46) Sandanayaka, A. S. D.; Araki, Y.; Ito, O.; Chitta, R.; Gadde, S.; 550 D'Souza, F. Chem. Commun. 2006, 4327.

551 (47) D’Souza, F.; Maligaspe, E.; Sandanayaka, A. S. D.; Subbaiyan, N. 552 K.; Karr, P. A.; Hasobe, T.; Ito, O. J. Phys. Chem. A 2010, 114, 10951. 553 (48) Maligaspe, E.; D’Souza, F. Org. Lett. 2010, 12, 624

554 (49) D’Souza, F.; Maligaspe, E.; Ohkubo, K.; Zandler, M. E.; 555 Subbaiyan, N. K.; Fukuzumi, S. J. Am. Chem. Soc. 2009, 131, 8787.

556 (50) Lu, X.; Feng, L.; Akasaka, T.; Nagase, S. Chem. Soc. Rev. 2012, $55741,7723$.

558 (51) Tsuchiya, T.; Sato, K.; Kurihara, H.; Wakahara, T.; Nakahodo, 559 T.; Maeda, Y.; Akasaka, T.; Ohkubo, K.; Fukuzumi, S.; Kato, T.; 560 Mizorogi, N.; Kobayashi, K.; Nagase, S. J. Am. Chem. Soc. 2006, 128, 5616699.

562 (52) Yamada, M.; Akasaka, T. Bull. Chem. Soc. Jpn. 2014, 87, 1289.

563 (53) Lu, X.; Akasaka, T.; Nagase, S. Acc. Chem. Res. 2013, 46, 1627.

564 (54) Akasaka, T.; Lu, X. Chem. Rec. 2012, 12, 256.

565 (55) Yamada, M.; Akasaka, T.; Nagase, S. Acc. Chem. Res. 2010, 43, 56692.

567 (56) Tsuchiya, T.; Kurihara, H.; Sato, K.; Wakahara, T.; Akasaka, T.; 568 Shimizu, T.; Kamigata, N.; Mizorogi, N.; Nagase, S. Chem. Commun. 569 2006, 3585.

570 (57) Supur, M.; Kawashima, Y.; Larsen, K. R.; Ohkubo, K.; Jeppesen, 571 J. O.; Fukuzumi, S. Chem. - Eur. J. 2014, 20, 13976.

572 (58) Supur, M.; Kawashima, Y.; Ma, Y.-X.; Ohkubo, K.; Chen, C.-F.; 573 Fukuzumi, S. Chem. Commun. 2014, 50, 15796.

574 (59) Girifalco, L. A.; Hodak, M.; Lee, R. S. Phys. Rev. B: Condens. 575 Matter Mater. Phys. 2000, 62, 13104.

576 (60) Ramesh, S.; Ericson, L. M.; Davis, V. A.; Saini, R. K.; Kittrell, C.; 577 Pasquali, M.; Billups, W. E.; Adams, W. W.; Hauge, R. H.; Smalley, R. 578 E. J. Phys. Chem. B 2004, 108, 8794.

579 (61) Holzinger, M.; Vostrowsky, O.; Hirsch, A.; Hennrich, F.; 580 Kappes, M.; Weiss, R.; Jellen, F. Angew. Chem., Int. Ed. 2001, 40, 4002.

581 (62) Dyke, C. A.; Tour, J. M. J. Am. Chem. Soc. 2003, 125, 1156.

582 (63) Zhang, X.; Sreekumar, T. V.; Liu, T.; Kumar, S. J. Phys. Chem. B 583 2004, 108, 16435.

584 (64) Kahn, M. G. C.; Banerjee, S.; Wong, S. S. Nano Lett. 2002, 2, 5851215.

586 (65) Banerjee, S.; Kahn, M. G. C.; Wong, S. S. Chem. - Eur. J. 2003, 9, 5871898 .

588 (66) Jiang, C.; Saha, A.; Xiang, C.; Young, C. C.; Tour, J. M.; 589 Pasquali, M.; Martí, A. A. ACS Nano 2013, 7, 4503.

590 (67) Anderson, R. E.; Barron, A. R. J. Nanosci. Nanotechnol. 2007, 7, 5913436.

592 (68) Sainsbury, T.; Fitzmaurice, D. Chem. Mater. 2004, 16, 2174.

593 (69) Perez, E. M.; Martin, N. Chem. Soc. Rev. 2015, 44, 6425.

594 (70) D'Souza, F.; Chitta, R.; Sandanayaka, A. S. D.; Subbaiyan, N. K.; 595 D’Souza, L.; Araki, Y.; Ito, O. Chem. - Eur. J. 2007, 13, 8277.

596 (71) D’Souza, F.; Chitta, R.; Sandanayaka, A. S. D.; Subbaiyan, N. K.; 597 D’Souza, L.; Araki, Y.; Ito, O. J. Am. Chem. Soc. 2007, 129, 15865.

598 (72) Vizuete, M.; Gómez-Escalonilla, M. J.; Fierro, J. L. G.; 599 Sandanayaka, A. S. D.; Hasobe, T.; Yudasaka, M.; Iijima, S.; Ito, O.; 600 Langa, F. Chem. - Eur. J. 2010, 16, 10752.

601 (73) Vizuete, M.; Gomez-Escalonilla, M. J.; Fierro, J. L. G.; Ohkubo, 602 K.; Fukuzumi, S.; Yudasaka, M.; Iijima, S.; Nierengarten, J.-F.; Langa, 603 F. Chem. Sci. 2014, 5, 2072.

604 (74) Ballesteros-Garrido, R.; de Miguel, M.; Domenech-Carbo, A.; 605 Alvaro, M.; Garcia, H. Chem. Commun. 2013, 49, 3236.

606 (75) Olsen, G.; Ulstrup, J.; Chi, Q. ACS Appl. Mater. Interfaces 2016, 6078,37 .

608 (76) Guo, J.; Lee, J.; Contescu, C. I.; Gallego, N. C.; Pantelides, S. T.; 609 Pennycook, S. J.; Moyer, B. A.; Chisholm, M. F. Nat. Commun. 2014, 6105,5389 .
(77) Wei, W.; Xu, C.; Ren, J.; Xu, B.; Qu, X. Chem. Commun. 2012, 611 48, 1284.

612

(78) Kellner, I. D.; von Gernler, M. S.; Tzirakis, M. D.; 613 Orfanopoulos, M.; Drewello, T. J. Phys. Chem. C 2014, 118, 30253.614

(79) Kellner, I. D.; von Gernler, M. S.; Tzirakis, M. D.; 615 Orfanopoulos, M.; Drewello, T. J. Phys. Chem. C 2016, 120, 786.616

(80) Bourgeois, J.-P.; Echegoyen, L.; Fibbioli, M.; Pretsch, E.; 617 Diederich, F. Angew. Chem., Int. Ed. 1998, 37, 2118. 